\title{
Synthesis of Phosphinines from Co"-Catalyzed [2+2+2] Cycloaddition Reactions
}

\author{
Tim Gläsel, Haijun Jiao,* and Marko Hapke*
}

Cite This: ACS Catal. 2021, 11, 13434-13444

Read Online

ABSTRACT: The $\mathrm{Co}^{\mathrm{II}}$-catalyzed $[2+2+2]$ cycloaddition of functionalized diynes and phosphaalkynes resulting in the formation of an array of structurally interesting phosphinines is reported. A combination of 1,2-bis(diphenylphosphino)benzene (dppbenz) and $\mathrm{CoI}_{2}$ turned out to be the most suitable and active catalyst system under microwave reaction conditions. Chemoselective cyclizations of phosphaalkynes in the presence of nitriles have been observed, and a number of carbonyl functionalities are tolerated as well. The reaction can successfully be conducted with a 1:1 ratio of phosphaalkyne/diyne substrate. Model reactions with

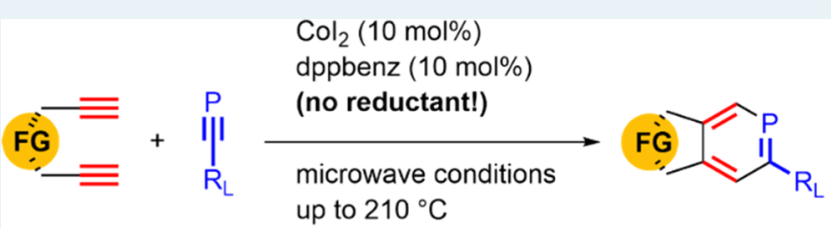

(substrate ratio 1:1)
Yields up to $91 \%$ benzonitrile and diyne demonstrated that $\mathrm{Co}^{\mathrm{II}}$ catalysts in the presence of bisphosphines prefer carbocyclization, while reduction to lower oxidation states promotes heterocyclization to the corresponding pyridine. A reaction mechanism comprising a $\mathrm{Co}^{\mathrm{II}}$ oxidation state for the cyclotrimerization process is proposed and rationalized based on control experiments and theoretical calculations.

KEYWORDS: cobalt, $[2+2+2]$ cycloaddition, phosphaalkynes, phosphinines, pyridines, reaction mechanism

\section{INTRODUCTION}

Catalytic $[2+2+2]$ cycloadditions of alkynes and heterocumulenes, leading to a wealth of functionalized aromatic and heteroaromatic molecules, have become an interesting synthetic strategy for the assembly of complex molecules from structurally simpler precursors since the onset of the first systematic studies. ${ }^{1,2}$ The development also includes the introduction of various catalysts from the whole range of transition metals. ${ }^{3}$ The large variety of metal complexes available for cyclotrimerizations is also manifested in the diversity of reaction mechanisms. ${ }^{4}$ Cobalt compounds have always taken a front seat in the application of late transitionmetal catalysts in cyclotrimerization reactions, especially by cyclopentadienyl ( $\mathrm{Cp}$ ) $\mathrm{Co}^{\mathrm{I}}$-(neutral ligand) complexes like $\mathrm{CpCo}(\mathrm{CO})_{2}{ }^{5}$ or modified congeners. ${ }^{6}$ A number of in situ generated $\mathrm{Co}^{\mathrm{I}}$ complexes from the reduction of $\mathrm{Co}^{\mathrm{II}}$ halides containing bisphosphine or NHC ( $N$-heterocyclic carbene) ligands have been utilized for the transformation of triynes to furnish highly substituted benzenes. ${ }^{7}$ Also the isolable complex $\mathrm{CoCl}\left(\mathrm{PPh}_{3}\right)_{3}$ was identified as a useful molecularly defined precatalyst for this transformation under mild conditions. ${ }^{8}$ The reaction scope has also been extended to asymmetric cyclizations by an in situ generated chiral $\mathrm{Co}^{\mathrm{I}}-(\mathrm{P}, \mathrm{N}$ ligand) catalyst, affording atropochiral biaryls and triaryls.'

While pyridines belong to the core area of heteroaromatic chemistry, phosphinines (also coined phosphabenzenes) have a much shorter history. ${ }^{10}$ However, their molecular properties, e.g., in comparison to pyridines, ${ }^{11}$ in homogeneous catalysis ${ }^{12}$ and coordination chemistry, ${ }^{13,14}$ have stirred significant work over recent decades toward their synthesis and functionalization. ${ }^{15}$ De novo synthesis of phosphinines by transition-metalcatalyzed reactions besides traditional approaches like the [4+2] cycloaddition of phosphaalkynes with 2-pyrones is still rare (Scheme 1, top).

A single example is reported for the reaction of sodium phosphaethynolate with alkynes to furnish the sodium phosphinin-4-olate in two $[2+2]$ cycloaddition events (Scheme 1 , middle). ${ }^{16}$ The only known successful transition-metalcatalyzed cyclization of phosphaalkynes was reported by Nishibayashi and co-workers, applying $\mathrm{FeI}_{2}$ without additional ligands, proposing an $\mathrm{Fe}^{\mathrm{II}} / \mathrm{Fe}^{\mathrm{IV}}$ catalytic reaction cycle (Scheme 1, middle). ${ }^{17}$ However, an excess of the valuable phosphaalkyne building block is required in this reaction. The unusual and successful application of an $\mathrm{Fe}^{\mathrm{II}}$ halide as a catalyst raises the question of whether higher cobalt oxidation states can potentially also be useful in facilitating cyclotrimerization processes. While $\mathrm{CpCo}^{\mathrm{I}}$ complexes are established catalysts for pyridine ring assembly under a variety of conditions, a large tendency toward dimerization of the phosphaalkynes using

Received: August 3, 2021

Revised: September 7, 2021

Published: October 21, 2021 
Scheme 1. Synthesis of Phosphinines ( $R=$ Bulky Alkyl or Aryl Groups)

Classical route for phosphinine synthesis via Diels-Alder-type synthesis of phosphaethynes with 2-pyrones:

$$
\mathrm{N}_{0}^{0}+\prod_{\mathrm{R}}^{\mathrm{P}} \frac{\Delta}{-\mathrm{CO}_{2}}
$$

Consecutive [2+2] cycloadditions of phosphaethynolate with alkynes:<smiles>[C]OC(=O)c1c([NH2+]O)c(-c2ccccc2)c(C(=O)OCC)c(-c2ccccc2)c1-c1ccccc1</smiles>

Fe"l-catalyzed [2+2+2] cycloaddition of diynes and phosphaalkynes:

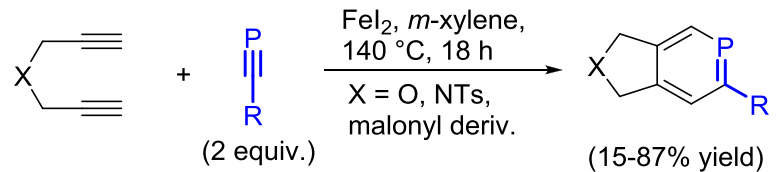

Co ${ }^{\prime \prime}$-catalyzed [2+2+2] cycloaddition of diynes and phosphaalkynes (this work):

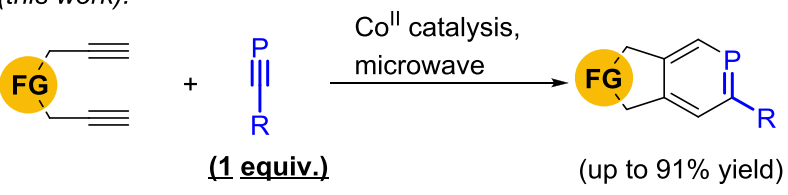

Functional Groups comprising cyclizations in the presence of, e.g. nitrile, lactone, sulfoxide or ester groups in the substrate

different $\mathrm{CpCo}^{\mathrm{I}}$ complexes was observed, leading to the formation of highly stable diphosphabutadienes. ${ }^{18}$ This behavior can be traced back to the properties of phosphaalkynes, which rather reflect alkynes than nitriles. Only recently, the successful application of $\mathrm{Co}^{\mathrm{II}}$ complexes in hydroformylation reactions was reported. ${ }^{19}$ In the following, we disclose our results on the unprecedented $\mathrm{Co}^{\mathrm{II}}$-catalyzed synthesis of functionalized phosphabenzenes. To the best of our knowledge, such type of reaction has never been reported for cobalt-catalyzed cyclotrimerizations to date (Scheme 1, below). ${ }^{20}$

\section{RESULTS AND DISCUSSION}

Initial experiments applied reactions of dipropargylether (1a) with the commercially available adamantylphosphaalkyne (2a) in the presence of cobalt salts in different oxidation states (Scheme 2). For $\mathrm{CoCl}\left(\mathrm{PPh}_{3}\right)_{3}$ and $\mathrm{Co}(\mathrm{acac})_{3} / \mathrm{dppe}(1,2-$ bis(diphenylphosphino)ethane), neither cyclization (3a) nor at least homocyclization of 1a to the 1a_dimer was observed, and no cyclization products could be isolated at all. Inspired by our current experiments, applying $\mathrm{CoI}_{2}$ as $\mathrm{Co}^{\mathrm{II}}$ salt together with dppe as ligand, without the presence of a typical reductant like elemental zinc, led to the successful cyclization furnishing phosphabenzene 3a with $36 \%$ isolated yield at high temperatures under microwave conditions.

This outcome inspired us to investigate the unusual cyclization mode of $\mathrm{Co}^{\mathrm{II}}$ catalysts in the presence of chelating ligands for phosphaalkyne/diyne substrates in detail, as $\mathrm{Co}^{\mathrm{II}}$ would present a rather unusual oxidation state to catalyze cyclotrimerizations. Preliminary tests with $\mathrm{Co}^{\mathrm{II}}$ salts in the presence of a reductant like elemental zinc or manganese did not give any useful yields, distinctly hinting at the requirement of $\mathrm{Co}^{\mathrm{II}}$ in the active catalyst. However, in the absence of such reductants the reaction proceeded as described above. We have set out to use dipropargyl diethylmalonate $(\mathbf{1 b})$ as substrate for cyclizations with $\mathbf{2 a}$ using conventional heating as well as microwave conditions (Table 1$).^{21}$

The results in Table 1 were obtained for a $1: 1$ ratio of $\mathbf{1 b}: \mathbf{2} \mathbf{a}$, which is remarkable in view of the observation that 2 equiv of phosphaalkyne are required for the $\mathrm{Fe}$-catalyzed reaction. ${ }^{17 \mathrm{a}}$ Initial tests showed a significant yield (35\%) of phosphinine $3 \mathbf{b}$ for dppe as ligand in only one case (entry 9), while under all other conditions (entries $1-3,5-8$ ), only very small amounts or no product formation was observed. Control experiments with $\mathrm{CoCl}\left(\mathrm{PPh}_{3}\right)_{3}$ under identical conditions did not show any cyclization at all (entry 4). Cyclizations with bisphosphines possessing larger bite angles (entries 10 and 11) or dppe derivatives (entry 12 ) gave either no or a maximum $20 \%$ yield of $3 \mathbf{b}$. When applying 1,2-bis(diphenylphosphino)benzene (dppbenz) as ligand, essentially all investigated $\mathrm{Co}^{\mathrm{II}}$ halides successfully performed the $[2+2+2]$ cycloaddition process, with yields of $39 \%(\mathrm{X}=\mathrm{Cl}$, entry 18$)$, up to $69 \%(\mathrm{X}=\mathrm{Br}$, entries $13-15)$ or even $80 \%(X=I$, entry 19$)$ for the desired phosphinine $\mathbf{3 b}$.

Remarkably, the reaction was usually run at $180-210^{\circ} \mathrm{C}$ for a reaction time of 1 to $4 \mathrm{~h}$. A lower temperature $\left(100{ }^{\circ} \mathrm{C}\right)$ requires a significantly longer reaction time to deliver a

Scheme 2. Cobalt Complexes in Different Oxidation States in the Cyclization of 1a and 2a

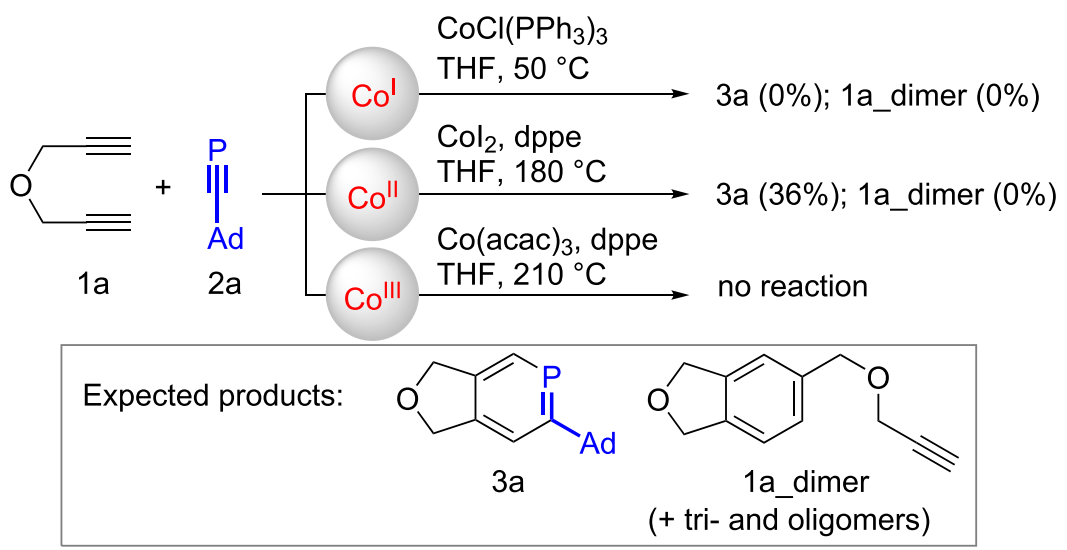


Table 1. Optimization of Reaction Conditions

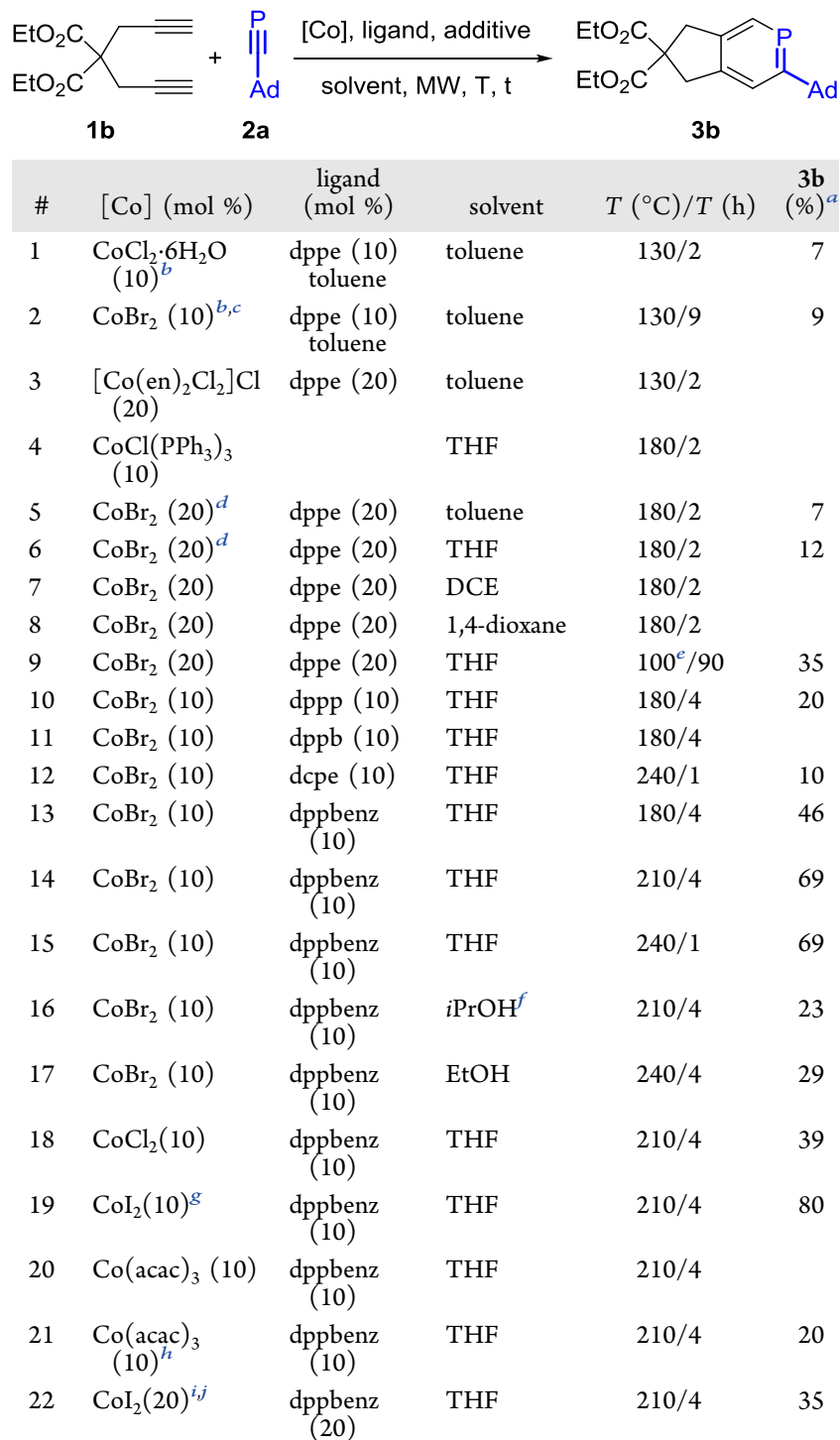

${ }^{a}$ Isolated yield. ${ }^{b}$ Addition of $20 \mathrm{~mol} \% \mathrm{Zn}$. ${ }^{c}$ Addition of $20 \mathrm{~mol} \%$ $\mathrm{ZnI}_{2}$. ${ }^{d}$ Addition of $40 \mathrm{~mol} \% \mathrm{Zn}$ and $\mathrm{ZnI}_{2}$. ${ }^{e}$ Performed with conventional heating without microwave. ${ }^{f}$ Performed with technical standard purity. ${ }^{g}$ Short period of sonication before heating. ${ }^{h}$ Addition of $10 \mathrm{~mol} \% \mathrm{Zn} .{ }^{i}$ Addition of $20 \mathrm{~mol} \%$ of $\mathrm{Zn}$ and heating to $60{ }^{\circ} \mathrm{C}$ for 1 h. ${ }^{j}$ Addition of $20 \mathrm{~mol} \%$ [C $\left.\mathrm{Cp}_{2} \mathrm{Fe}\right] \mathrm{PF}_{6}$.

reasonable yield (entry 9). The utilization of $\mathrm{Co}(\mathrm{acac})_{3}$ as Co ${ }^{\text {III }}$ salt together with dppbenz under otherwise identical conditions did not yield any $3 \mathbf{b}$, excluding $\mathrm{Co}^{\mathrm{III}}$ from being responsible for cyclizations (entry 20). Further corroboration came from an experiment, when under the same conditions 10 mol \% elemental zinc was added to the $\mathrm{Co}(\mathrm{acac})_{3} / \mathrm{dppbenz}$ mixture, yielding $20 \%$ of $3 \mathbf{b}$ (entry 21 ). It is reasonable to assume a preceding reduction of $\mathrm{Co}^{\mathrm{III}}$ to $\mathrm{Co}^{\mathrm{II}}$ by zinc and then cyclization of $\mathbf{1 b}$ with $\mathbf{2 a}$ was possible to occur.

In another control experiment, $\mathrm{CoI}_{2} / \mathrm{dppbenz}$ was first reduced with elemental zinc to $\mathrm{Co}^{\mathrm{I}}$, which was then reoxidized with stoichiometric amounts of ferrocenium hexafluorophosphate back to $\mathrm{Co}^{\mathrm{II}}$, easily recognizable by color change after addition of each reagent (entry 22). The resulting catalyst solution performed the cyclization with $35 \%$ yield of $\mathbf{3 b}$.

After having evaluated the reaction conditions, we were interested in the scope of substrates utilizing the most efficient catalyst system. ${ }^{22}$ Especially the structural variations of the diyne substrates were of high interest (Chart 1). In all transformations investigated, again the favorable 1:1 substrate ratio of functionalized diyne/phosphaalkyne was applied.

Phosphinines $\mathbf{3 a}$ and $\mathbf{3 b}$ were isolated using the optimized catalytic system either from diynes $\mathbf{1 a}$ or $\mathbf{1} \mathbf{b}$ and $\mathbf{2 a}$ in reliably excellent yields. The presence of the carboxylic ester group in

Chart 1. Screening of Substrate Scope for the Synthesis of Phosphinines (Isolated Yields)
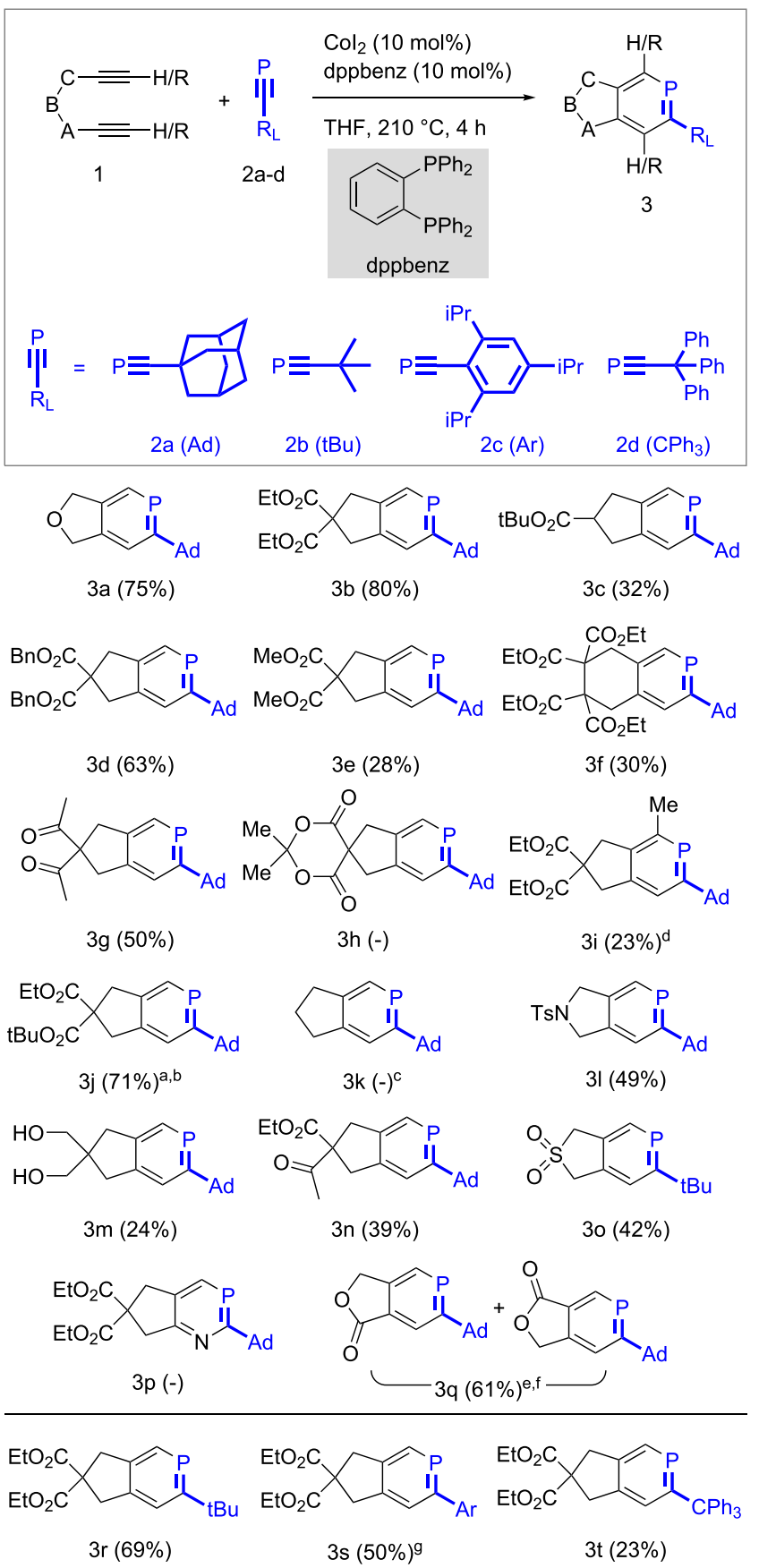

${ }^{a}$ Microwave at $160{ }^{\circ} \mathrm{C}$ for $16 \mathrm{~h} .{ }^{b}$ Mixture containing two isomers, the shown product $3 \mathbf{j a}$ and the mono-decarboxylated product $3 \mathbf{j b}$ in a ratio of 4:5; see the Supporting Information (SI). ${ }^{c}$ Product formed only in traces. ${ }^{d}$ Mixture of two regioisomers in a ratio of $10: 3$, the major isomer is displayed. ${ }^{e}$ Microwave at $140{ }^{\circ} \mathrm{C}$ for $4 \mathrm{~h}$. ${ }^{f}$ Both regioisomers combined. ${ }^{g}$ Microwave at $240{ }^{\circ} \mathrm{C}$ for $1 \mathrm{~h}$. 
the diyne seemed to have a significant influence on the yields. The mono-tert-butyl ester product (3c) and malonate methyl ester product (3e) were obtained with yields around 30\%, while the malonate benzyl ester (3d) was furnished with a good yield (63\%). Tetracarboxylate-substituted diynes were possible to cyclize with $\mathbf{2 a}$, affording the six-membered ringannellated phosphinine $3 \mathrm{f}$ with a $30 \%$ yield. Cyclization of 4 diacetylated 1,6-heptadiynes gave phosphinine $3 \mathrm{~g}$ with at least $50 \%$ yield, while a Meldrum's acid-based diyne (substrate for 3h) gave no product, presumably due to diyne decomposition at such high reaction temperature. The reaction of terminally monosubstituted diynes (3i) gave only low yield (23\%).

Unsymmetrical malonate esters with large alkyl groups underwent decarboxylation, resulting in a mixture of both, regioisomers $3 \mathbf{j}$ and decarboxylation product, but no complete selective decarboxylation could be achieved. The cyclization of unsubstituted 1,6-heptadiyne only gave traces of product $3 \mathbf{k}$. Substrates with combined keto/ester functionality, dipropargyl tosylamide or even diynes containing free hydroxyl groups gave phosphinines $3 \mathbf{l}, \mathbf{3 m}$, and $3 \mathbf{n}$ in isolated yields of up to $49 \%$. The cyclization of sulfonyl-bridged diynes has been rarely investigated but can be accomplished with at least $42 \%$ yield (3o). ${ }^{23}$ Application of a cyanoalkyne to construct a P,N heterocycle, such as $3 \mathrm{p}$, was investigated but did not furnish the desired product under these reaction conditions. An esterbridged diyne was successfully transformed at a lower reaction temperature $\left(140{ }^{\circ} \mathrm{C}\right)$ to prevent decomposition, allowing isolation of $3 \mathrm{q}$ as two regioisomers with a total yield of $61 \%$. To elucidate the scope of the reaction, other phosphaalkynes were exemplarily investigated as well. Utilizing tert-butylphosphaethyne (2b) as substrate with $\mathbf{1 b}$ afforded phosphinine $\mathbf{3 r}$ with a good yield (69\%). The assembly of the biaryl product $3 \mathrm{~s}$ using the novel sterically demanding 2,4,6-triisopropylphenyl phosphaethyne (2c) was achieved with a 50\% yield, which required heating at $240{ }^{\circ} \mathrm{C}$ for $1 \mathrm{~h}$. Finally, deploying the sterically demanding triphenylmethyl phosphaethyne (2d) and $\mathbf{~} \mathbf{b}$ furnished the phosphinine $3 \mathbf{t}$ with a lower yield (23\%) due to its bulkiness and multiple possible side reactions, exemplarily demonstrated for ruthenium promoted phosphindole formation by Grützmacher and co-workers. ${ }^{24}$ The complete intermolecular $[2+2+2]$ cycloaddition between phenylacetylene as terminal alkyne and $\mathbf{2 a}$ was also shortly investigated for our $\mathrm{Co}^{\mathrm{II}}$ catalyst system, but finally resulted repeatedly in the polymerization of phenylacetylene, presumably due also to the high reaction temperatures applied $\left(210{ }^{\circ} \mathrm{C}\right.$ under standard conditions $) .{ }^{25}$

To further develop the applicability of our phosphinine synthesis protocol, we have screened propargylated malonitrile derivatives $4 \mathbf{a}-\mathbf{e}$ as cyclization components with phosphaalkynes $\mathbf{2 a - d}$. We were especially interested in the chemoselectivity of the cyclization as both $\mathrm{C} \equiv \mathrm{N}$ and $\mathrm{C} \equiv \mathrm{P}$ were present in the reaction mixtures. Interestingly, only phosphinine formation was observed, thus establishing a systematic access to a novel class of nitrile-substituted phosphinines enabling further derivatization (Chart 2). Under our established catalytic conditions, the transformations took place with satisfying yields for all investigated nitrilesubstituted substrates and phosphaalkynes $\mathbf{2 a / 2}$ b (yields $30-$ $91 \%$ ), without the formation of any pyridine products. The product isolation was easily done by chromatography as the formed phosphinines $\mathbf{5 a} \mathbf{a} \mathbf{i}$ are reasonably stable. Isolated nitrile-substituted phosphinine $\mathbf{5} \mathbf{f}$ emerged to be stable at room temperature on air at least for three months, whereas in
Chart 2. Synthesis of Nitrile-Substituted Phosphinines (Isolated Yields)

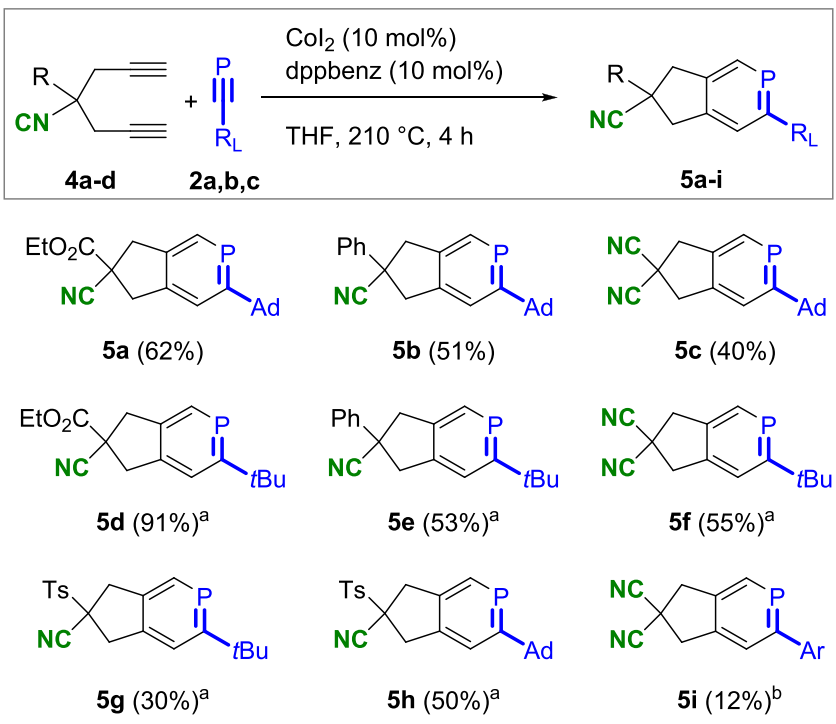

${ }^{a}$ Microwave heating for $22 \mathrm{~min}$ to $240{ }^{\circ} \mathrm{C}$. ${ }^{b}$ Microwave heating for $2 \mathrm{~h}$ to $240{ }^{\circ} \mathrm{C}$.

solution or as an oil, decomposition processes could be observed over time. Cyclization of the 2,4,6-triisopropylphenylsubstituted phosphaethyne (2c) with malononitrile $4 \mathrm{c}$ gave only $12 \%$ yield in the case of malononitrile $5 \mathbf{i}$ at even $240^{\circ} \mathrm{C}$. This phosphaalkyne appears to be of less reactivity and sterically very bulky; therefore, inferior results were obtained. Following the decoration with nitrile and ester groups, the synthesized molecules offer interesting potential for further functionalization.

We were able to obtain single crystals of phosphinine $\mathbf{5 c}$ for structural characterization by X-ray diffraction as shown in Figure $1 .^{26}$ The structure clearly shows the deviation of the heteroaromatic ring with the phosphorus atom compared to a pure carbocyclic ring system with equidistant space between the ring carbons.

The $\mathrm{C}-\mathrm{C}$ distances are only varying marginally in the range of $1.383(2)-1.395(2) \AA$, while the bond length between C-5-

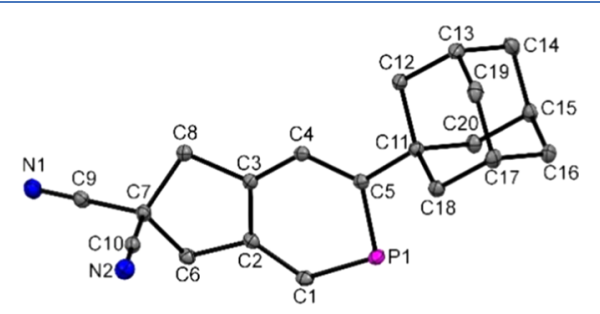

Figure 1. Molecular structure of phosphinine 5c. Displacement ellipsoids correspond to $30 \%$ probability. Hydrogen atoms are omitted for clarity.

P-1 $(1.7587(14) \AA)$ is significantly elongated compared to the nonanellated phosphinine (1.739 $\AA$ ), whereas the bond length of C-1-P-1 (1.7293(15) $\AA$ ) shows a significantly smaller deviation, ${ }^{27}$ indicating the delocalized character of the sixmembered ring system. Comparing the ${ }^{31} \mathrm{P}$ NMR shifts from the furnished anellated phosphinines with the unsubstituted pure phosphinine, most cases show little shielding, ranging from $193.1 \mathrm{ppm}(\mathbf{3} \mathbf{j b})$ to $198.5 \mathrm{ppm}(\mathbf{3 a})$, in contrast to 206.5 
ppm for $\mathrm{C}_{5} \mathrm{H}_{5} \mathrm{P} .{ }^{28}$ Aryl substituents lead to a slight deshielding of the phosphorus atom for $3 \mathbf{s}$ and $3 \mathbf{t}$, whereas the electronwithdrawing effects of the carbonyl carbon in meta position to phosphorus are resulting in a significantly higher deshielding with a resonance at $245.0 \mathrm{ppm}$ for the lactone 3q. The nitrilebearing phosphinines (5) are exhibiting slightly shifted resonances, culminating in a ${ }^{31} \mathrm{P}$ NMR signal of $212.2 \mathrm{ppm}$ for $5 \mathbf{i}$.

Our synthetic protocol was further exemplarily investigated toward the manufacture of synthetically useful amounts of substituted phosphinine 5f. Allowing slightly longer reaction times and lower temperatures (technical limitation by the used microwave), $\mathbf{5 f}$ was isolated in a $55 \%$ yield on a 10 times larger scale without reduction of yield (Scheme 3).

Scheme 3. Large-Scale Preparation of Phosphinine 5f by [2+2+2] Cycloaddition (10-Fold Upscaling, $1.5 \mathrm{mmol})$

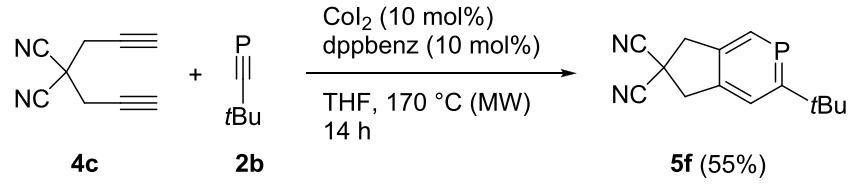

To expand the synthetic useability, a functional-groupdecorated phosphinine was exemplarily assembled, demonstrating the tolerance of the developed phosphinine formation for alkynes and acetals in the backbone (Scheme 4). The

Scheme 4. Synthesis of Alkyne-Functionalized Phosphinines $7 a$ and $7 b$

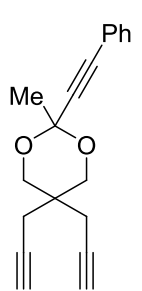

6

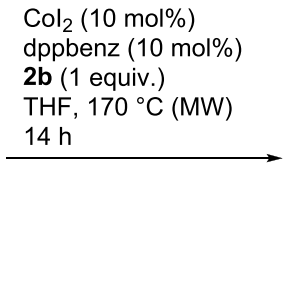

dppbenz (10 mo 2b (1 equiv.) HF, $170^{\circ} \mathrm{C}(\mathrm{MW})$ $14 \mathrm{~h}$

\section{.}

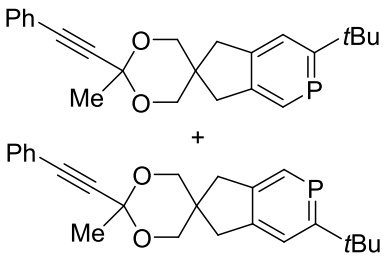

7a+b (combined yield: $37 \%$ ) reaction of 6 with $2 b$ resulted in the formation of two regioisomers $7 \mathbf{a} / 7 \mathbf{b}$ in a $1: 1$ ratio with a $37 \%$ yield. In contrast to Meldum's acid-based cyclic diyne ( $3 \mathbf{h}$, Chart 1 ), the functionalized acetal in 6 proved to be stable enough for the reaction conditions. The formed phosphinine core of $7 \mathbf{a} / 7 \mathbf{b}$ remained intact upon unsuccessful attempts to transform the remaining phenylacetylene substituent, e.g., by $\mathrm{Cp} * \mathrm{RuCl}-$ (COD)-catalyzed [3+2] cycloaddition with phenylazide to substituted triazoles. However, the substrate 7 could always be quantitatively recovered.

$\mathrm{Co}^{\mathrm{II}}$ complexes are commonly used as precursors in cyclotrimerization reactions; however, an in situ reduction with elemental zinc is usually mandatory to furnish the catalytically active $\mathrm{Co}^{\mathrm{I}}$-catalyst. Only for a homo-Diels-Alder reaction, $\mathrm{Co}^{\mathrm{II}}$ catalysis has been proposed by Binger and Albus. ${ }^{20}$ Adding $\mathrm{ZnI}_{2}$ as Lewis acid to $\mathrm{CoI}_{2}\left(\mathrm{PPh}_{3}\right)_{2}$ furnished cationic species like $\left[\mathrm{CoI}\left(\mathrm{PPh}_{3}\right)_{2}\right]^{+}\left[\mathrm{ZnI}_{3}\right]^{-}$or $[\mathrm{Co}-$ $\left.\left(\mathrm{PPh}_{3}\right)_{2}\right]^{2+}\left[\mathrm{ZnI}_{3}\right]^{2-}$, acting as catalysts for the cyclization. During our study, we recognized that $\mathrm{Co}^{\mathrm{I}}$ and $\mathrm{Co}^{\mathrm{III}}$ complexes are not performing the described cycloaddition reactions but rather a $\mathrm{Co}^{\mathrm{II}}$ species. This was independently confirmed by either selective oxidation of $\mathrm{Co}^{\mathrm{I}}$ or reduction of $\mathrm{Co}^{\mathrm{III}}$ complexes to the formal $\mathrm{Co}^{\mathrm{II}}$ complexes leading in each case to cyclotrimerization activity, as was experimentally proven (Table 1, entries 21 and 22). A 1:1 stoichiometry of $\mathrm{CoX}_{2} /$ bisphosphine was essential, as a 1:2 ratio with a second ligand was shutting down the catalytic activity completely.

The compatibility of catalytic systems for the transformation of structural variations of a substrate often reveals interesting information on the catalyst itself. For example, we deployed the catalyst system found for phosphinine formation in the reaction of diynes and nitriles, intending to furnish pyridines in the same manner (Table 2). Results quickly showed no formation of the expected pyridine (9), but rather homocyclization of $\mathbf{1 b}$ to $\mathbf{1 b}$ dimer and presumably tri- and oligomers (Table 2, entry 1). For further detailed investigations, we evaluated dppe as ligand, which was also proofed suitable for cyclizations with phosphaalkynes (e.g., Table 1, entry 9) and also nitriles. ${ }^{29}$ Initial experiments using solely $\mathrm{CoI}_{2}$ and dppe without any additive in tetrahydrofuran (THF) solution gave mostly 1b_dimer with small amounts of the pyridine 9 (10\%, Table 2, entry 2). Changing reaction temperature and reaction time did not give general changes; however, lower temperatures and longer times only led to an increase of the formed trimers and oligomers from $\mathbf{1} \mathbf{b} .^{30}$ It should be noted that pyridine formation with $\mathrm{Co}^{\mathrm{II}}$ complexes was observed at a significantly lower temperature compared to phosphinine formation. Evaluating cobalt sources showed that use of $\mathrm{CoCl}_{2}$ and even more $\mathrm{CoBr}_{2}$ gave higher yields of pyridine 9 (12 and 20\%, Table 2, entries 3 and 4); therefore, we decided to use $\mathrm{CoBr}_{2}$ also due to its better solubility for further experimentation. It is a current matter of discussion how the oxidation state of the active cobalt catalyst plays a distinguished role in the synthesis of nitrogen heterocycles, as it is illustrated by a very recent literature example. ${ }^{31} \mathrm{We}$ followed that impetus by adding elemental zinc to investigate the changes in product contribution. The trend observed by several experiments including an increasing amount of zinc is quite clear (Table 2, entries 5-7). Utilizing 4 equiv of zinc finally furnished nearly exclusively the pyridine product 9 with a $80 \%$ yield at $180{ }^{\circ} \mathrm{C}$ (Table 2, entry 7 ). Lowering the reaction temperature to $100{ }^{\circ} \mathrm{C}$ and prolonging the reaction time under otherwise identical conditions exclusively yielded 9 with a $50 \%$ yield (Table 2, entry 8 ). Control experiments without cobalt (Table 2, entry 9) or without dppe ligand (Table 2, entry 10) gave either no yield or only carbocyclus 1b dimer with a $29 \%$ yield like in the latter case. The utilization of a ligand-free low-valent cobalt catalyst system from $\mathrm{CoBr}_{2}$ and elemental zinc for the successful cyclotrimerization of a triyne has been observed before, featuring rather a $\mathrm{Co}^{\mathrm{I}}$ species as a catalyst than a $\mathrm{Co}^{0}$ species. ${ }^{8}$ Initial investigation of different reactivities for $\mathrm{Co}^{0}$ and ligand-free $\mathrm{Co}^{\mathrm{I}}$ species as well as $\mathrm{CpCo}(\mathrm{CO})_{2}$ with diynes in the presence of nitriles and phenylacetylene already showed strong deviations in reactivity depending on the oxidation state and ligand presence. ${ }^{32}$

Following our experiments, we proposed the involvement of a Co ${ }^{\text {II }}$-bisphosphine complex as starting species in the catalytic cycle. Interestingly, in most cases, the reactions proceeded rather straightforward at high temperatures to afford phosphinines as sole isolable products after work-up. Clearly and in contrast to the $\mathrm{Fe}$-catalyzed cyclization, ${ }^{17 \mathrm{a}}$ the choice of ligand for cobalt does play a decisive role in the cycloaddition process. A tentative reaction mechanism is displayed in Chart 3. The first step would be generation of the active catalyst 
Table 2. Investigation of the Reaction Conditions for Pyridine Formation

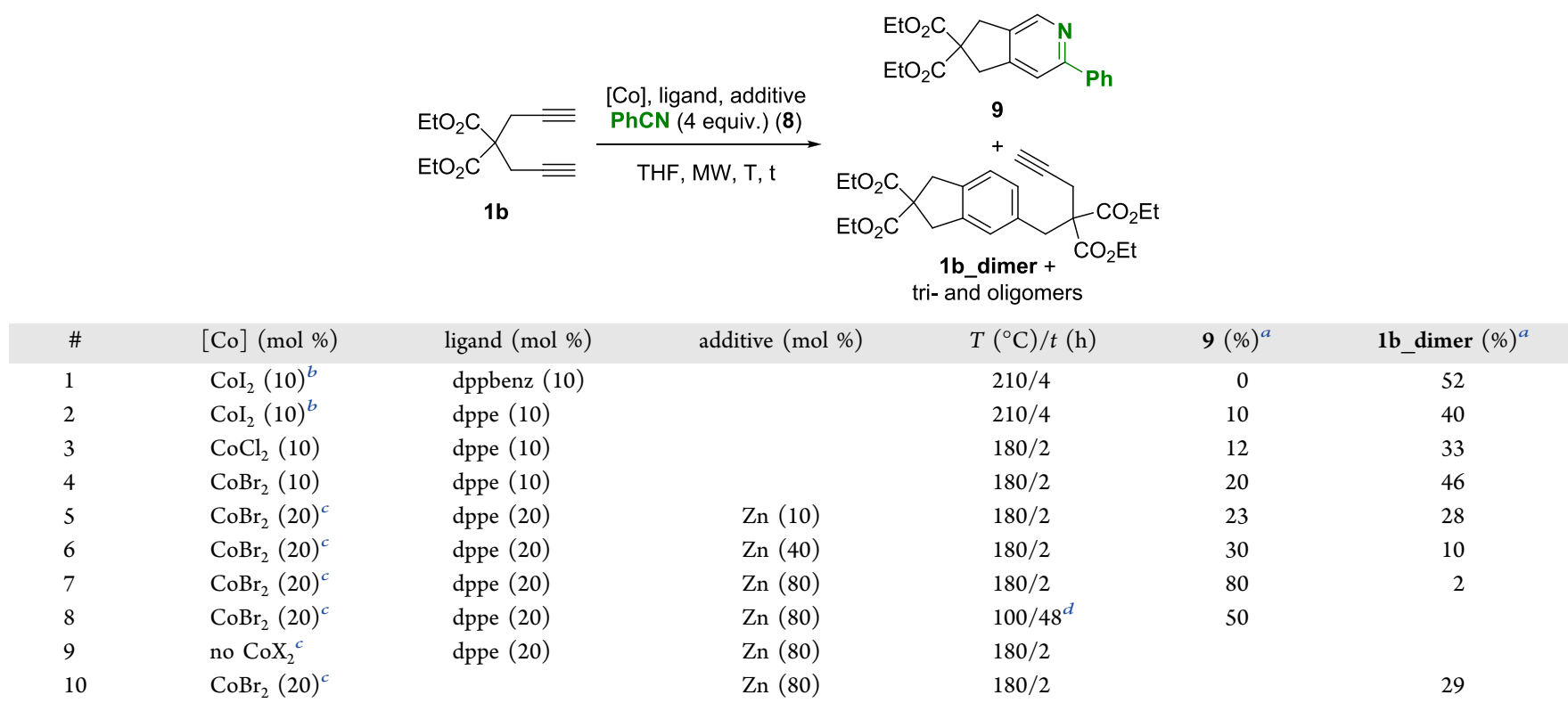

${ }^{a}$ For the complete screening, see Table S2 in the SI. Yield of isolated product. ${ }^{b}$ Short period of sonication before heating. ${ }^{c}$ Cobalt source, ligand, and zinc were heated to $60^{\circ} \mathrm{C}$ for $1 \mathrm{~h}$ before the substrates were added. ${ }^{d}$ Performed with conventional heating without microwave.

Chart 3. Proposed Reaction Mechanism for the Co ${ }^{\mathrm{II}}$ Catalyzed Synthesis of Phosphinines from Diynes and Phosphaalkynes ( $\mathrm{L}=$ dppbenz, $\mathrm{X}=$ halide $)$<smiles>[X]C1Pc2ccccc2P1c1ccccc1</smiles><smiles>[R]c1cc2c(cp1)COC2</smiles>

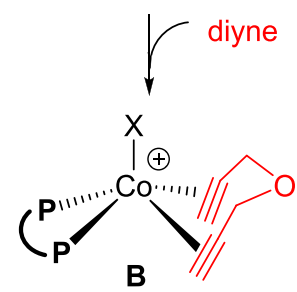

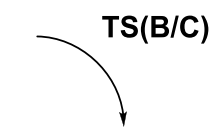<smiles></smiles>

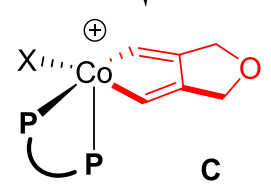

TS(F/G) $\uparrow$<smiles>[R]C1=PC([R])=P[PH]([Z])([Z])C=C2COCC2=C1</smiles>

TS(E/F)

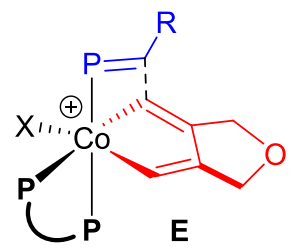

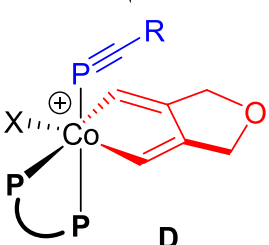

TS(D/E)

species by halide dissociation, leading to cationic complex A, which upon coordination of diyne 1a gave a cationic squarepyramidal diyne complex B. Subsequently, formation of a

$\mathrm{Co}^{\mathrm{IV}}$-cyclopentadiene complex (C) would occur via $\mathrm{C}-\mathrm{C}$ oxidative coupling. ${ }^{33}$ Next, coordination of phosphaalkyne to the $\mathrm{Co}^{\mathrm{IV}}$ center forms intermediate $\mathrm{D}$ and a formal $[2+2]$ cycloaddition leads to intermediate $\mathbf{E}$, which rearranges to seven-membered intermediate F. Finally, reductive elimination gives the intermediate $\mathbf{G}$ as a catalyst-product complex, from which the phosphinine is released and coordination of another diyne starts the next catalytic cycle.

On the basis of this proposal, we carried out density functional theory computations to explore the potential free energy surface and the computational details are given in the Supporting Information. Geometry optimization was carried out in gas phase at the $\mathrm{BP} 86^{34}$ level with the all-electron $\mathrm{TZVP}^{35}$ basis set for nonmetal elements as well as the effective core potential (ECP) of Hay and Wadt with double- $\zeta$ valence basis set $\mathrm{LANL}_{2} \mathrm{DZ}^{36}$ for the iodine atom. All optimized structures were further characterized at the same level either as energy minimums without imaginary frequencies or transition states with only one imaginary frequency by frequency calculations, which provide zero-point vibrational energies and thermal corrections to enthalpy and Gibbs free energy at 298.15 K under 1 atmosphere. On the basis of the BP86 optimized geometries in gas phase, single-point energies at the M06L ${ }^{37}$ level with the same basis sets under the consideration of solvation effect of THF as solvent based on solute electron density (SMD) ${ }^{38}$ were computed. The final Gibbs free energies for discussion were calculated from the M06L single-point energies and the thermal correction to Gibbs free energy from B3P86 at 298 and $443 \mathrm{~K}$. In recent studies of cobalt complexes with different spin states, ${ }^{39,40}$ M06L showed the best agreement with experiment in the thermodynamic parameters. All calculations were carried out using the Gaussian 16 program. $^{41}$

The reaction is initiated by halide dissociation from the precursor complex $\mathrm{CoX}_{2}$ (dppbenz), further discussed as $\mathrm{CoX}_{2} \mathrm{~L}$. First, we computed the structure and stability of the precursor complexes, $\mathrm{CoX}_{2} \mathrm{~L}$. For $\mathrm{CoX}_{2} \mathrm{~L}$, the quartet spin state is more stable than the doublet spin state by $3.7,6.5$, and 4.7 
$\mathrm{kcal} / \mathrm{mol}$ for $\mathrm{X}=\mathrm{Cl}, \mathrm{Br}$, and $\mathrm{I}$, respectively. The dissociation Gibbs free energy $\left[\mathrm{CoX}_{2} \mathrm{~L}=\mathrm{CoX}^{+} \mathrm{L}+\mathrm{X}^{-}\right]$is 66.4, 76.2, and $58.1 \mathrm{kcal} / \mathrm{mol}$ for $\mathrm{X}=\mathrm{Cl}, \mathrm{Br}$, and $\mathrm{I}$, respectively (Chart 4 ).

\section{Chart 4. Halide Dissociation from $\operatorname{CoX}_{2} \mathrm{~L}$}

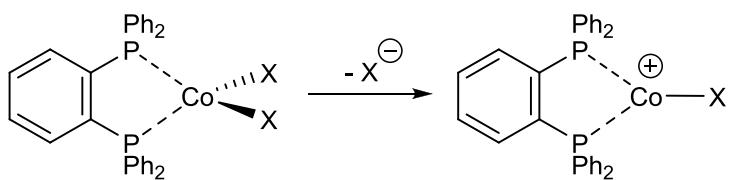

$$
\begin{aligned}
& \mathrm{CoX}_{2} \mathrm{~L} \\
& (\mathrm{X}=\mathrm{Cl}, \mathrm{Br}, \mathrm{I}) \\
& A_{\mathrm{Cl}}\left(\Delta G_{\text {diss }}=66.4 \mathrm{kcal} / \mathrm{mol}\right) \\
& A_{\mathrm{Br}}\left(\Delta G_{\text {diss }}=76.2 \mathrm{kcal} / \mathrm{mol}\right) \\
& \text { A } \quad\left(\Delta G_{\text {diss }}=58.1 \mathrm{kcal} / \mathrm{mol}\right)
\end{aligned}
$$

For the monocationic complex $\mathbf{A},[\mathrm{CoXL}]^{+}$, the doublet spin state is more stable than the quartet spin state by $1.1,6.5$, and $0.7 \mathrm{kcal} / \mathrm{mol}$ for $\mathrm{X}=\mathrm{Cl}, \mathrm{Br}$, and $\mathrm{I}$, respectively, revealing the possible exchange of spin states under thermodynamic equilibrium. The quartet ground state of $\mathrm{CoX}_{2} \mathrm{~L}$ has tetrahedral Co coordination and the low-lying excited double state has distorted planar Co coordination. On the contrary, the doublet ground state of $[\mathrm{CoXL}]^{+}$has nearly triangular planar Co coordination and the low-lying excited quartet state has trigonal pyramidal Co coordination. For $\mathrm{X}=\mathrm{Cl}$, the nearly triangular planar doublet ground state is more stable than the nonplanar structure by only $2.4 \mathrm{kcal} / \mathrm{mol}$ and such a small energy difference indicates the possibility of flexible coordination of the chloride ligand.
Based on these results, we computed the $[2+2+2]$ cyclization of diynes and phosphaalkyne using $[\mathrm{CoClL}]^{+}$ $\left(\mathbf{A}_{\mathrm{Cl}}\right)$ as a catalyst and dipropargylether (1a) and tertbutylphosphaethyne $(\mathbf{2 b})$ as substrates. The coordination of 1a and the subsequent cyclization have several coordination isomers, $\mathrm{C}-\mathrm{C}$ coupling transition states, and products, and only the most stable isomers are used for discussion (Figure $S 1)$. As shown in the potential Gibbs free energy profiles (Chart 5), the formation of complex $\mathbf{B}\left[\mathbf{A}_{\mathbf{C l}}+\mathbf{1} \mathbf{a}=\mathbf{B}\right]$ is exergonic by $2.9 \mathrm{kcal} / \mathrm{mol}$, indicating a very weak coordination. The subsequent oxidative $\mathrm{C}-\mathrm{C}$ coupling via transition state TS(B/C) has a Gibbs free energy barrier of $5.8 \mathrm{kcal} / \mathrm{mol}$ and the formation of the cobaltacyclopentadiene intermediate $(\mathbf{C})$ is exergonic by $19.4 \mathrm{kcal} / \mathrm{mol}$, indicating a thermodynamically and kinetically very easily accessible step. Due to the very close energy between the doublet and quartet states of the precatalyst and active catalyst, we computed the quartet state of complex $\mathbf{B}$, which is more stable than the double state by 4.9 $\mathrm{kcal} / \mathrm{mol}$. However, the corresponding quartet transition state TS $(B / C)$ is less stable than the doublet state by $10.4 \mathrm{kcal} / \mathrm{mol}$, and quartet intermediate $\mathbf{C}$ is less stable than the double state by $13.4 \mathrm{kcal} / \mathrm{mol}$. Thus, our discussion follows the doublet potential energy surface.

Starting from isomer $\mathbf{C}, \mathbf{2} \mathbf{b}$ coordination to form intermediate $\mathbf{D}$ is endergonic by $8.2 \mathrm{kcal} / \mathrm{mol}$, and the corresponding $2 \mathrm{~b}$ insertion via transition state $\mathrm{TS}(\mathrm{D} / \mathrm{E})$ has a Gibbs free energy barrier of $3.5 \mathrm{kcal} / \mathrm{mol}$ and the formation of the insertion product $\mathbf{E}$ is exergonic by $25.6 \mathrm{kcal} / \mathrm{mol}$. Starting from intermediate $\mathbf{E}$, it is not possible to locate the corresponding seven-membered metallacycle $(\mathbf{F})$ for reductive elimination, and attempts to optimize intermediate $\mathbf{F}$ results in the direct formation of the final reductive eliminated product

Chart 5. Gibbs Free Energy (kcal/mol, $298 \mathrm{~K})$ Profiles at M06L-SCRF/TZVP for Intermediates of the Catalytic Cycle $(Q$ for the Energy of the Corresponding Quartet State)

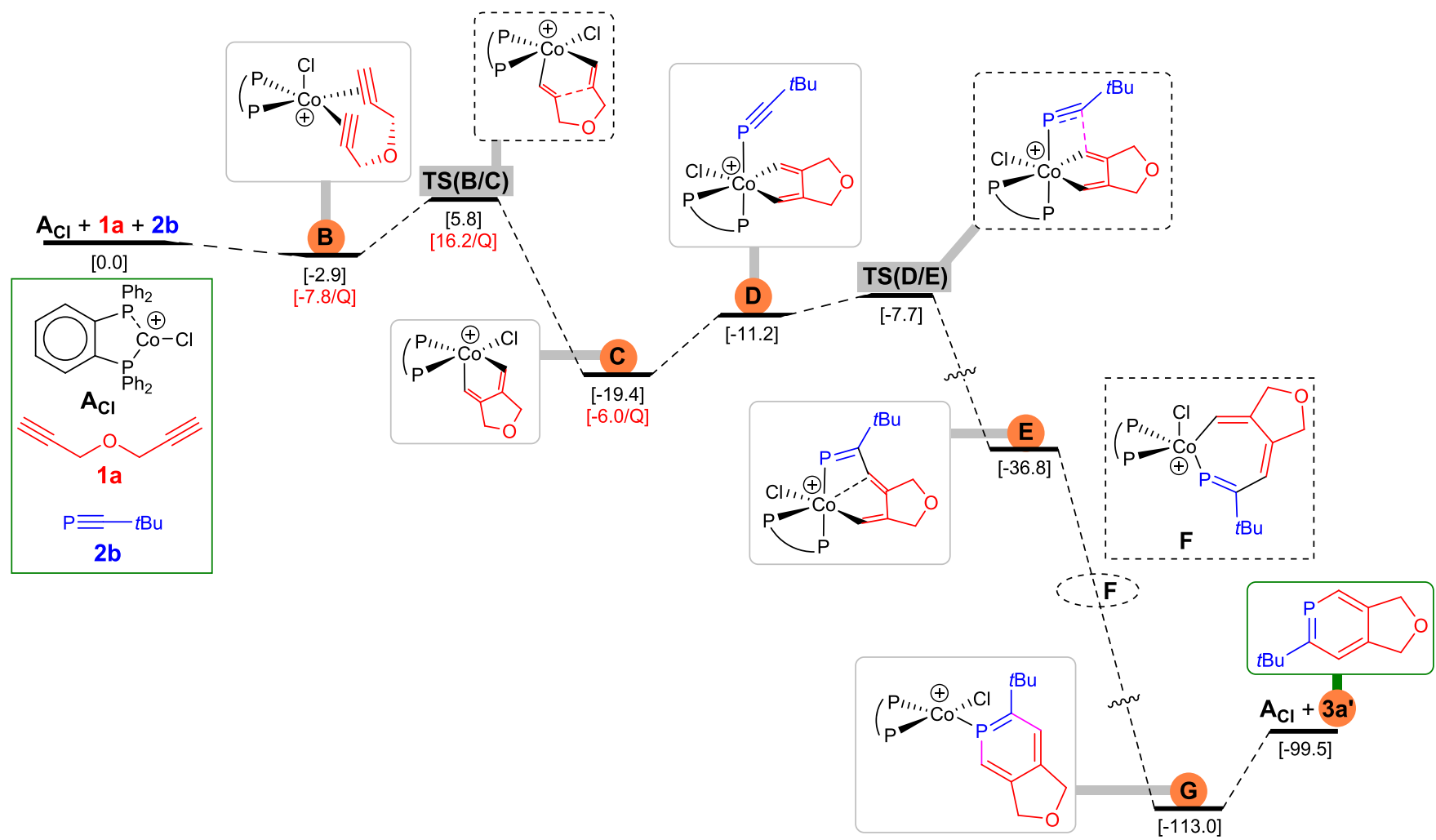


intermediate $(\mathbf{G})$. The rearrangement from $\mathbf{E}$ to $\mathbf{G}$ is very exergonic by $76.2 \mathrm{kcal} / \mathrm{mol}$ and such huge downhill energy might explain the failure of not being able to locate intermediate F. Finally, release of product $\left(3^{\prime}\right)$ and regeneration of active catalyst $\mathbf{A}$ is endergonic by $13.5 \mathrm{kcal} /$ mol.

The Gibbs free energy profiles in Chart 5 show that from the monocationic $\mathbf{A}$ as active catalyst, $\mathbf{T S}(\mathbf{B} / \mathbf{C})$ represents the highest point $(5.8 \mathrm{kcal} / \mathrm{mol})$ and also the rate-determining step, while the total reaction is very exergonic by $99.5 \mathrm{kcal} /$ mol. In addition, we also computed the $\mathbf{T S}(\mathrm{B} / \mathrm{C})$ for $\mathrm{X}=\mathrm{Br}$ and I, and the Gibbs free energy is 4.5 and $10.2 \mathrm{kcal} / \mathrm{mol}$, respectively. All of these show that this reaction should be very easy and fast on the basis of the comparably low barriers and $\mathrm{X}=\mathrm{I}$ should have lower activity due to the highest barrier. However, these results are not in agreement with the rather intense reaction condition $\left(>200{ }^{\circ} \mathrm{C}, 4 \mathrm{~h}\right)$ on the one hand, and the finding that $\mathrm{X}=\mathrm{I}$ is more active than $\mathrm{X}=\mathrm{Cl}$ and $\mathrm{Br}$ on the other hand. Since $\mathrm{CoX}_{2} \mathrm{~L}$ is found to have the stability order of $\mathrm{CoBr}_{2} \mathrm{~L}>\mathrm{CoCl}_{2} \mathrm{~L}>\mathrm{CoI}_{2} \mathrm{~L}$, we assumed that the kinetic activity should be associated with their stability. Therefore, we computed the apparent Gibbs free energy barrier starting from $\mathrm{CoX}_{2} \mathrm{~L}$, i.e., the Gibbs free energy difference between $\mathrm{CoX}_{2} \mathrm{~L}+1 \mathrm{a}$ and $\mathbf{T S}(\mathbf{B} / \mathrm{C})+\mathrm{X}^{-}$(Chart 6).

Chart 6. Apparent Barrier (443 K, kcal/mol) of the Oxidative Cyclization Step in Dependence on the Halide Counteranion of the Catalytic Species $(X=$ Halide $)$

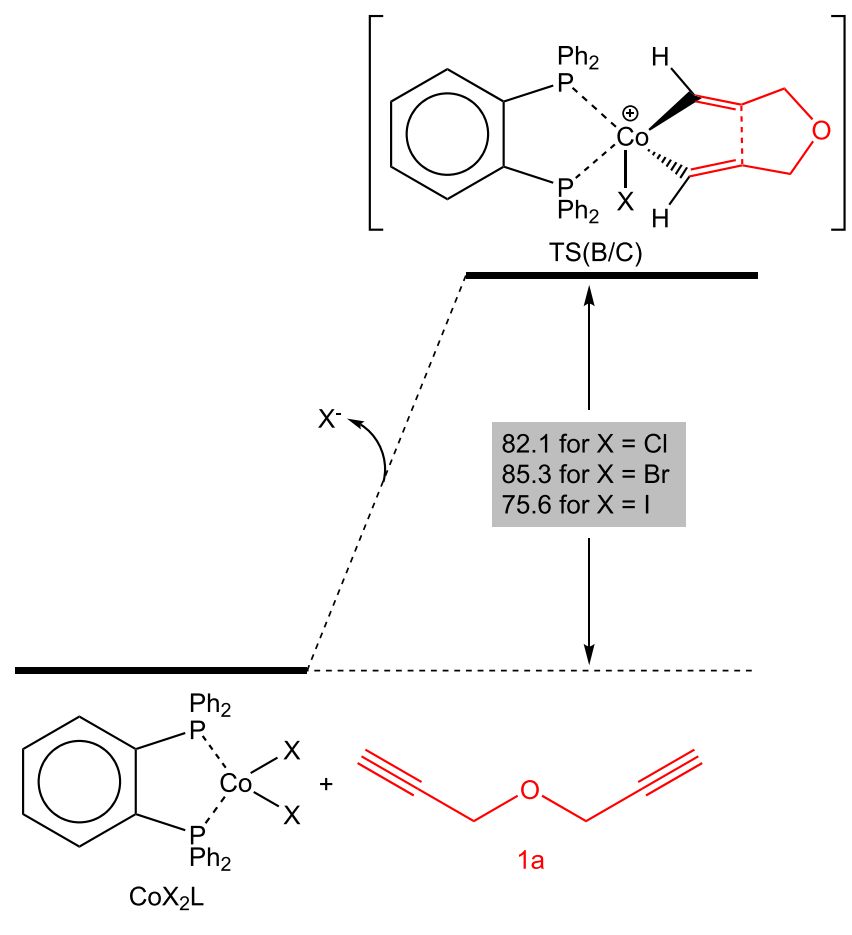

It is found that the apparent Gibbs free energy barrier is 82.1, 85.3 , and $75.6 \mathrm{kcal} / \mathrm{mol}$ for $\mathrm{X}=\mathrm{Cl}, \mathrm{Br}$, and $\mathrm{I}$ at $443 \mathrm{~K}$, respectively $(71.1,74.2$, and $68.3 \mathrm{kcal} / \mathrm{mol}$ for $\mathrm{X}=\mathrm{Cl}, \mathrm{Br}$, and I at $298 \mathrm{~K}$, respectively). Such high apparent barriers might explain the need of a rather high temperature and a long reaction time on the one hand, and the identified lowest apparent barrier for $\mathrm{X}=\mathrm{I}$ might also show the higher activity compared to $\mathrm{X}=\mathrm{Cl}$ and $\mathrm{Br}$. It is noted that such high apparent barriers are more qualitative than quantitative since it includes large electrostatic effects between an anion and a cation apart from coordination and excludes the counterions. Nevertheless, their difference can be used to explain the observed difference in activity.

Cyclizations with terminal diynes, as was observed in our syntheses, can lead to homocyclization products. We have therefore investigated the potential coordination of intermediate $\mathbf{C}$ and one $\mathrm{C} \equiv \mathrm{C}$ bond of substrate $\mathbf{1 a}$ with respect to the formation of homocyclization product 1a_dimer (see Scheme 2). The expected $\eta^{2}$-coordination of the alkyne $\mathrm{C} \equiv \mathrm{C}$ bond to $\mathbf{C}$ would lead to a similar structure like intermediate $\mathbf{D}$ in the case of the phosphaalkynes (Chart 5). However, structure optimization of such an intermediate led directly to the corresponding $\mathrm{Co}^{\mathrm{II}}$-coordinated product 1a_dimer, analogous to the formation of an intermediate $\mathbf{G}$ for the phosphinine product. This step for cyclization of $\mathbf{1 a}$ is even more exergonic than for phosphaalkyne $2 \mathbf{b}(-125.7$ vs -113.0 $\mathrm{kcal} / \mathrm{mol}$ ). However, the coordination of substrate to $\mathbf{C}$ via the heteroatom lone-pair (in the phosphaalkyne) vs the $\eta^{2}-\mathrm{C} \equiv \mathrm{C}$ coordination (in the diyne) should be more effective, which might explain the beneficial $1: 1$ substrate ratio for 1 and $2 .^{42}$

\section{CONCLUSION}

For the first time, we report on the efficient synthesis of functionalized phosphinines by $\mathrm{Co}^{\mathrm{II}}$-catalyzed $[2+2+2]$ cycloaddition from phosphaalkynes and functionalized diynes, allowing a high atom-economical 1:1 ratio of the substrate and yielding the products with up to $91 \%$ yield. The reaction tolerates functional groups such as esters, ketones, lactone, sulfone, and even nitriles to be present in the phosphinine products. The cyclization catalyst consists of a cobalt(II)bisphosphine complex without a reducing agent, and high reaction temperatures are required for successful and fast catalysis. The preference of $\mathrm{Co}^{\mathrm{II}}$ catalysis for the cyclization of $\mathrm{C} \equiv \mathrm{P}$ vs $\mathrm{C} \equiv \mathrm{N}$ bonds with diynes in contrast to lower cobalt oxidation states was also proven by test reactions with benzonitrile and diynes. Theoretical studies on the reaction mechanism suggest a unique $\mathrm{Co}^{\mathrm{II}} / \mathrm{Co}^{\mathrm{IV}}$ cycle at work in the catalytic cycle on the doublet potential energy surface. The prospects of the unusual $\mathrm{Co}^{\mathrm{II}}$ oxidation state catalysis for other substrate combinations and more complex molecules are currently evaluated in our laboratory.

\section{ASSOCIATED CONTENT}

\section{Supporting Information}

The Supporting Information is available free of charge at https://pubs.acs.org/doi/10.1021/acscatal.1c03483.

Detailed experimental information on the synthesis of starting materials and products, computational details, and spectral data for all synthesized compounds (PDF)

\section{AUTHOR INFORMATION}

\section{Corresponding Authors}

Haijun Jiao - Leibniz Institute for Catalysis e.V. (LIKAT), D18069 Rostock, Germany; (1) orcid.org/0000-0002-29475937; Email: haijun.jiao@catalysis.de

Marko Hapke - Institute for Catalysis (INCA), Johannes Kepler University Linz (JKU), A-4040 Linz, Austria; Leibniz Institute for Catalysis e.V. (LIKAT), D-18069 Rostock, Germany; 이이.org/0000-0001-7454-9184; Email: marko.hapke@jku.at 


\section{Author}

Tim Gläsel - Institute for Catalysis (INCA), Johannes Kepler University Linz (JKU), A-4040 Linz, Austria

Complete contact information is available at:

https://pubs.acs.org/10.1021/acscatal.1c03483

\section{Author Contributions}

The manuscript was written through contributions of all authors. All authors have given approval to the final version of the manuscript.

\section{Funding}

M.H. thanks the JKU for financial support.

\section{Notes}

The authors declare no competing financial interest.

\section{ACKNOWLEDGMENTS}

The authors thank Fabian Fischer for preparative assistance and are indebted to Kirill Faust and Dr. Anke Spannenberg for the determination of the single-crystal X-ray structure analysis of $5 c$.

\section{DEDICATION}

Dedicated to the memory of the authors' wonderful colleague Prof. Paul Kamer.

\section{REFERENCES}

(1) Transition-Metal-Mediated Aromatic Ring Construction; Tanaka, K., Ed.; John Wiley \& Sons: Hoboken, 2013; pp 1-807.

(2) Reviews: (a) Heller, B.; Hapke, M. The fascinating construction of pyridine ring systems by transition metal-catalysed $[2+2+2]$ cycloaddition reactions. Chem. Soc. Rev. 2007, 36, 1085-1094. (b) Varela, J. A.; Saá, C. Recent Advances in the Synthesis of Pyridines by Transition-Metal-Catalyzed $[2+2+2]$ Cycloaddition. Synlett 2008, 2571-2578. (c) Turek, P.; Kotora, M. Synthesis of pyridines by $[2+2+2]$-cyclotrimerization of alkynes with nitriles. Targets Heterocycl. Syst. 2009, 13, 175-200. (c) Shaaban, M. R.; ElSayed, R.; Elwahy, A. H. M. Construction of fused heterocycles by metal-mediated $[2+2+2]$ cyclotrimerization of alkynes and/or nitriles. Tetrahedron 2011, 67, 6095-6130. (d) Hua, R.; Abrenica, M. V. A.; Wang, P. Cycloaddition of Alkynes: Atom-Economic Protocols for Constructing Six-Membered Cycles. Curr. Org. Chem. 2011, 15, 712729. (e) Okamoto, S.; Sugiyama, Y. account From the Development of Catalysts for Alkyne and Alkyne-Nitrile $[2+2+2]$ Cycloaddition Reactions to Their Use in Polymerization Reactions. Synlett 2013, 24, 1044-1060. (f) Tanaka, K. Rhodium-Catalyzed [2+2+2] Cycloaddition for the Synthesis of Substituted Pyridines, Pyridones, and Thiopyranimines. Heterocycles 2012, 85, 1017-1043. Rhodium: (g) Thakur, A.; Louie, J. Advances in Nickel-Catalyzed Cycloaddition Reactions To Construct Carbocycles and Heterocycles. Acc. Chem. Res. 2015, 48, 2354-2365. Nickel: (h) Yamamoto, Y. Recent topics of $\mathrm{Cp}^{*} \mathrm{RuCl}$-catalyzed annulation reactions. Tetrahedron Lett. 2017, 58, 3787-3794. Ruthenium: (i) Kotha, S.; Lahiri, K.; Sreevani, G. Design and Synthesis of Aromatics through $[2+2+2]$ Cyclotrimerization. Synlett 2018, 29, 2342-2361. (j) Pla-Quintana, A.; Roglans, A. Chiral Induction in $[2+2+2]$ Cycloaddition Reactions. Asian J. Org. Chem. 2018, 7, 1706-1718. (k) Stará, I. G.; Starý, I. Helically Chiral Aromatics: The Synthesis of Helicenes by $[2+2+2]$ Cycloisomerization of $\pi$-Electron Systems. Acc. Chem. Res. 2020, 53, 144-158.

(3) Hapke, M.; Weding, N.; Kral, K. Cyclotrimerization Reactions of Alkynes. In Applied Homogeneous Catalysis with Organometallic Compounds; Wiley-VCH: Weinheim, 2018; Vol. 1, pp 375-409.

(4) (a) Yamamoto, K.; Nagae, H.; Tsurugi, H.; Mashima, K. Mechanistic understanding of alkyne cyclotrimerization on mononuclear and dinuclear scaffolds: [4+2] cycloaddition of the third alkyne onto metallacyclopentadienes and dimetallacyclopentadienes.
Dalton Trans. 2016, 45, 17072-17081. (b) Roglans, A.; Pla-Quintana, A.; Solà, M. Mechanistic Studies of Transition-Metal-Catalyzed [2+2+2] Cycloaddition Reactions. Chem. Rev. 2021, 121, 1894-1979. (5) Vollhardt, K. P. C. Cobalt-Mediated [2+2+2]-Cycloadditions: A Maturing Synthetic Strategy. Angew. Chem., Int. Ed. 1984, 23, 539556.

(6) (a) Jonas, K.; Deffense, E.; Habermann, D. Synthesis and Reactions of $\eta 5$-Cyclopentadienylbis(ethene)cobalt. Angew. Chem., Int. Ed. 1983, 22, 716-717. (b) Geny, A.; Agenet, N.; Iannazzo, L.; Malacria, M.; Aubert, C.; Gandon, V. Air-Stable $\{(\mathrm{C} 5 \mathrm{H} 5) \mathrm{Co}\}$ Catalysts for $[2+2+2]$ Cycloadditions. Angew. Chem., Int. Ed. 2009, 48, 1810-1813. (c) Hapke, M.; Weding, N.; Spannenberg, A. Highly Reactive Cyclopentadienylcobalt(I) Olefin Complexes. Organometallics 2010, 29, 4298-4304. (d) Thiel, I.; Jiao, H.; Spannenberg, A.; Hapke, M. Fine-Tuning the Reactivity and Stability by Systematic Ligand Variations in CpCoI Complexes as Catalysts for $[2+2+2]$ Cycloaddition Reactions. Chem. - Eur. J. 2013, 19, 2548-2554. (e) Thiel, I.; Spannenberg, A.; Hapke, M. Synthesis of Air-Stable and Recyclable CpCoI-Complexes. ChemCatChem 2013, 5, 2865-2868. (f) Fischer, F.; Pientka, T.; Jiao, H.; Spannenberg, A.; Hapke, M. $\mathrm{CpCo}(\mathrm{I})$ precatalysts for $[2+2+2]$ cycloaddition reactions: synthesis and reactivity. Catal. Sci. Technol. 2020, 10, 8005-8014.

(7) (a) Review: Gläsel, T.; Hapke, M. Cobalt-Catalyzed [2+2+2] Cycloaddidtions. In Cobalt in Catalysis and Synthesis; Wiley-VCH: Weinheim, 2020; Chapter 9, pp 287-335. Review: Original work: (a) Saino, N.; Kogure, D.; Okamoto, S. Intramolecular Cyclotrimerization of Triynes Catalyzed by N-Heterocyclic Carbene$\mathrm{CoCl}_{2} / \mathrm{Zn}$ or $-\mathrm{FeCl}_{3} / \mathrm{Zn}$. Org. Lett. 2005, 7, 3065-3067. (b) Saino, N.; Amemiya, F.; Tanabe, E.; Kase, K.; Okamoto, S. A Highly Practical Instant Catalyst for Cyclotrimerization of Alkynes to Substituted Benzenes. Org. Lett. 2006, 8, 1439-1442. (c) Sugiyama, Y.; Okamoto, S. Catalytic $[2+2+2]$ cycloaddition polymerization of diyne-nitrile monomers in the presence of $\mathrm{CoCl}_{2}-6 \mathrm{H}_{2} \mathrm{O} /$ diphosphine/Zn. J. Polym. Sci., Part A: Polym. Chem. 2016, 54, 345-351.

(8) Jungk, P.; Fischer, F.; Thiel, I.; Hapke, M. $\mathrm{CoCl}\left(\mathrm{PPh}_{3}\right)_{3}$ as Cyclotrimerization Catalyst for Functionalized Triynes under Mild Conditions. J. Org. Chem. 2015, 80, 9781-9793.

(9) Jungk, P.; Fischer, F.; Hapke, M. In Situ-Generated Chiral Co(I)-Catalyst for Asymmetric [2+2+2] Cycloadditions of Triynes. ACS Catal. 2016, 6, 3025-3029.

(10) History and general overview: (a) Märkl, G. Aromatic phosphorus heterocycles-synthesis, structure, and reactivity. Lect. Heterocycl. Chem. 1972, 1, 69-92. (b) Ashe, A. J., III The Route to Phosphabenzene and Beyond. Eur. J. Inorg. Chem. 2016, 2016, 572574. (c) Le Floch, P. Six-membered Rings: Phosphinines. In Phosphorus-Carbon Heterocyclic Chemistry: The Rise of a New Domain; Pergamon: Oxford, 2001; pp 485-533.

(11) (a) Weemers, J. J. M.; Wiecko, J.; Pidko, E. A.; Weber, M.; Lutz, M.; Müller, C. 2,4,6-Triarylphosphinines versus 2,4,6Triarylpyridines: An Investigation of the Differences in Reactivity between Structurally Related Aromatic Phosphorus and Nitrogen Heterocycles. Chem. - Eur. J. 2013, 19, 14458-14469. (b) Carrasco, A. C.; Pidko, E. A.; Masdeu-Bultó, A. M.; Lutz, M.; Spek, A. L.; Vogt, D.; Müller, C. 2-(2'-Pyridyl)-4,6-diphenylphosphinine versus 2-(2'pyridyl)-4,6-diphenylpyridine: an evaluation of their coordination chemistry towards $\mathrm{Rh}(\mathrm{I})$. New J. Chem. 2010, 34, 1547-1550.

(12) (a) Weber, L. Phosphorus Heterocycles: From Laboratory Curiosities to Ligands in Highly Efficient Catalysts. Angew. Chem., Int. Ed. 2002, 41, 563-572. (b) Müller, C.; Vogt, D. Phosphinines as ligands in homogeneous catalysis: recent developments, concepts and perspectives. Dalton Trans. 2007, 5505-5523.

(13) Recent reviews: (a) Müller, C.; Broeckx, L. E. E.; de Krom, I.; Weemers, J. J. M.Developments in the Coordination Chemistry of Phosphinines. Eur. J. Inorg. Chem. 2013, 2013, 187-202. (b) Coles, N. T.; Sofie Abels, A.; Leitl, J.; Wolf, R.; Grützmacher, H.; Müller, C. Phosphinine-based ligands: Recent developments in coordination chemistry and applications. Coord. Chem. Rev. 2021, 433, No. 213729.

(14) Original work: (a) Müller, C.; Pidko, E. A.; Totev, D.; Lutz, M.; Spek, A. L.; van Santen, R. A.; Vogt, D. Atropoisomeric phosphinines: 
design and synthesis. Dalton Trans. 2007, 5372-5375. (b) Müller, C.; Pidko, E. A.; Lutz, M.; Spek, A. L.; Vogt, D. Diphosphinine derivatives of terpyridine: a newclass of neutral p-accepting pnp-pincer ligands. Chem. - Eur. J. 2008, 14, 8803-8807. (c) Müller, C.; Pidko, E. A.; Staring, A. J. P. M.; Lutz, M.; Spek, A. L.; van Santen, R. A.; Vogt, D. Developing a new class of axial chiral phosphorus ligands: preparation and characterization of enantiopure atropisomeric phosphinines. Chem. - Eur. J. 2008, 14, 4899-4905. (d) Müller, C.; Freixa, Z.; Lutz, M.; Spek, A. L.; Vogt, D.; van Leeuwen, P. W. N. M. Wide-BiteAngle Diphosphinines: Design, Synthesis, and Coordination Properties. Organometallics 2008, 27, 834-838. (e) Newland, R. J.; Smith, A.; Smith, D. M.; Fey, N.; Hanton, M. J.; Mansell, S. M. Accessing Alkyl- and Alkenylcyclopentanes from Cr-Catalyzed Ethylene Oligomerization Using 2-Phosphinophosphinine Ligands. Organometallics 2018, 37, 1062-1073. (f) Chen, X.; Li, Z.; Grützmacher, H. Multidentate Phosphanyl Phosphinines: Synthesis and Properties. Chem. - Eur. J. 2018, 24, 8432-8437. (g) Cleaves, P. A.; Mansell, S. M. Unexpected Multiple Coordination Modes in Silyl-Bridged Bis(phosphinine) Complexes. Organometallics 2019, 38, 1595-1605. (15) Selected examples: (a) Mao, Y.; Mathey, F. A Phosphinine 2Carboxaldehyde. Org. Lett. 2012, 14, 1162-1163. (b) Kostenko, N.; Ericsson, C.; Engqvist, M.; Gonzalez, S. V.; Bayer, A. Palladium(0)Catalyzed Cross-Couplings of 2-Bromophosphinine. Eur. J. Org. Chem. 2013, 2013, 4756-4759. (c) Zagidullin, A. A.; Ganushevich, Y. S.; Kafiyatullina, A. G.; Miluykov, V. A.; Sinyashin, O. G. Reactions of 1-ethyl-1,2-diphosphole with acetylenes. Russ. Chem. Bull. 2015, 64, 1986-1988. (d) Habicht, M. H.; Wossidlo, F.; Weber, M.; Müller, C. 3-Bromo-2-Pyron:An Alternative and Convenient Route to Functionalized Phosphinines. Chem. - Eur. J. 2016, 22, 12877-12883. (e) Polezhaev, A. V.; Beagan, D. M.; Cabelof, A. C.; Chen, C.-H.; Caulton, K. G. A substituent-tolerant synthetic approach to N/P"loaded" heteroarenes. Dalton Trans. 2018, 47, 5938-5942. (f) Hansmann, M. M. Synthesis of Azaphosphinines by Directed Inverse-Electron-Demand Hetero-Diels-Alder Reactions with Na(OCP). Chem. - Eur. J. 2018, 24, 11573-11577. (g) Habicht, M. H.; Wossidlo, F.; Bens, T.; Pidko, E. A.; Müller, C. 2-(Trimethylsilyl)- $\lambda^{3}$ Phosphinine: Synthesis, Coordination Chemistry, and Reactivity. Chem. - Eur. J. 2018, 24, 944-952. (h) Mei, Y.; Wu, D. J.; Borger, J. E.; Grützmacher, H. Simple Synthesis of Functionalized 2Phosphanaphthalenes. Angew. Chem., Int. Ed. 2018, 57, 5512-5515. (i) Yang, Z.; Chen, H.; Li, B.; Guo, W.; Jie, K.; Sun, Y.; Jiang, D.-e.; Popovs, I.; Dai, S. Topotactic Synthesis of PhosphabenzeneFunctionalized Porous Organic Polymers: Efficient Ligands in $\mathrm{CO}_{2}$ Conversion. Angew. Chem., Int. Ed. 2019, 58, 13763-13767. (j) Giese, S.; Klimov, K.; Mikeházi, A.; Kelemen, Z.; Frost, D. S.; Steinhauer, S.; Müller, P.; Nyulászi, L.; Müller, C. 2-(Dimethylamino)phosphinine: A Phosphorus-Containing Aniline Derivative. Angew. Chem., Int. Ed. 2021, 60, 3581-3586.

(16) Chen, X.; Alidori, S.; Puschmann, F. F.; Santiso-Quinones, G.; Benkő, Z.; Li, Z.; Becker, G.; Grützmacher, H.-F. Sodium Phosphaethynolate as a Building Block for Heterocycles. Angew. Chem., Int. Ed. 2014, 53, 1641-1645.

(17) (a) Nakajima, K.; Takata, S.; Sakata, K.; Nishibayashi, Y. Synthesis of Phosphabenzenes by an Iron-Catalyzed $[2+2+2]$ Cycloaddition Reaction of Diynes with Phosphaalkynes. Angew. Chem., Int. Ed. 2015, 54, 7597-7601. (b) Nakajima, K.; Liang, W.; Nishibayashi, Y. Iron-Catalyzed [2+2+2] Cycloaddition Reactions of Diynes with Oxyphosphaethynes To Construct 2-Phosphaphenol Derivatives. Org. Lett. 2016, 18, 5006-5009.

(18) (a) Hitchcock, P. B.; Maah, M. J.; Nixon, J. F. First example of cyclodimerisation of a phosphaalkyne to a 1,3-diphosphacyclobutadiene. Syntheses of complexes of the type $\left[\mathrm{M}\left(\eta^{5}-\mathrm{C}_{5} \mathrm{R}_{5}\right)\left\{\eta^{4}\right.\right.$ $\left.\left.\left(\mathrm{Bu}{ }^{\mathrm{t}} \mathrm{CP}\right)_{2}\right\}\right] \mathrm{R}=\mathrm{H}$ or Me; $\mathrm{M}=\mathrm{Co}, \mathrm{Rh}$, or Ir): crystal and molecular structure of $\eta^{5}$-pentamethylcyclopentadienyl-2,4-di-t-butyl-1,3diphosphacyclobutadienecobalt(I), $\left[\mathrm{Co}\left(\eta^{5}-\mathrm{C}_{5} \mathrm{Me}_{5}\right)\left\{\eta^{4}-\left(\mathrm{Bu}{ }^{t} \mathrm{CP}\right)_{2}\right\}\right]$. J. Chem. Soc., Chem. Commun. 1986, 737-738. (b) Matos, R. M.; Nixon, J. F.; Okuda, J. Cyclodimerisation and addition reactions of $\mathrm{Bu}^{\mathrm{t}} \mathrm{CP}$ at a cobalt(I) centre. Inorg. Chim. Acta 1994, 222, 13-20.
(19) Hood, D. M.; Johnson, R. A.; Carpenter, A. E.; Younker, J. M.; Vinyard, D. J.; Stanley, G. G. Highly active cationic cobalt(II) hydroformylation catalysts. Science 2020, 367, 542-548.

(20) Only single reports describe the use of $\mathrm{Co}(\mathrm{II})$ salts without reductant in a related Homo-Diels-Alder reaction as a special variant of the $[2+2+2]$ cycloaddition: Binger, P.; Albus, S. Deltacyclene formation catalysed by cationic $\mathrm{Co}$ (II) complexes. J. Organomet. Chem. 1995, 493, C6-C8.

(21) The complete screening table can be found in the SI, pp 21-23.

(22) By using $\mathrm{CoI}_{2}$ as cobalt(II) source, sonication was applied to reaction mixture before heating for a short time at room temperature for better solubilization of the commercially available pellets/balls of $\mathrm{CoI}_{2}$.

(23) (a) Grigg, R.; Scott, R.; Stevenson, P. Rhodium-catalysed [2+ $2+2$ ]-cycloadditions of acetylenes. J. Chem. Soc., Perkin Trans. 1 1988, 1357-1364. (b) Kotha, S.; Sreevani, G. A Short Synthetic Route to Benzosultine-sulfone using Rongalite and $[2+2+2]$-Cyclotrimerization. ChemistrySelect 2017, 2, 10804-10808.

(24) Cordaro, J. G.; Stein, D.; Grützmacher, H. A synthetic cycle for the ruthenium-promoted formation of $1 \mathrm{H}$-phosphindoles from phosphaalkynes. J. Am. Chem. Soc. 2006, 128, 14962-14971.

(25) Control of the reaction progress by ${ }^{31} \mathrm{P}$ NMR spectroscopy showed no formation of the expected phosphinine product at all.

(26) Deposition Number CCDC 2024641 contains the supplementary crystallographic data for this paper. These data are provided free of charge by the joint Cambridge Crystallographic Data Centre and Fachinformationszentrum Karlsruhe Access Structures service www.ccdc.cam.ac.uk/structures.

(27) Jonas, V.; Frenking, G. The molecular structure of phosphabenzene. A theoretically predicted correction to the experimentally determined $\mathrm{C}-\mathrm{C}$ bond lengths. Chem. Phys. Lett. 1993, 210, 211-215.

(28) Elschenbroich, C.; Six, J.; Harms, K.; Frenking, G.; Heydenrych, G. $\eta^{1}$-Coordination of Phosphinine $\mathrm{C}_{5} \mathrm{H}_{5} \mathrm{P}$ and Arsenine $\mathrm{C}_{5} \mathrm{H}_{5}$ As to Ruthenium(II) and Osmium(II). Eur. J. Inorg. Chem. 2008, 2008, 3303-3309.

(29) As examples for nitriles, see: (a) Chang, H.-T.; Jeganmohan, M.; Cheng, C.-H. Cobalt-Catalyzed Intramolecular [2+2+2] Cocyclotrimerization of Nitrilediynes: An Efficient Route to Tetraand Pentacyclic Pyridine Derivatives. Org. Lett. 2007, 9, 505-508. (b) Sugiyama, Y.; Okamoto, S. Regioselective Syntheses of Substituted Pyridines and 2,2'-Bipyridines by Cobalt-Catalyzed $[2+2+2]$ Cycloaddition of $\alpha, \omega$-Diynes with Nitriles. Synthesis 2011, $2247-2254$.

(30) For the complete screening table see the SI, pp 42-43.

(31) Wang, C.-S.; Sun, Q.; García, F.; Wang, C.; Yoshikai, N. Robust Cobalt Catalyst for Nitrile/Alkyne [2+2+2] Cycloaddition: Synthesis of Polyarylpyridines and Their Mechanochemical Cyclodehydrogenation to Nitrogen-Containing Polyaromatics. Angew. Chem., Int. Ed. 2021, 60, 9627-9634.

(32) Chiusoli, G. P.; Pallini, L.; Terenghi, G. Different chemoselectivities in cobalt(0)- and cobalt(I)-catalyzed cyclocotrimerization of $\mathrm{C} \equiv \mathrm{C}$ and $\mathrm{C} \equiv \mathrm{N}$ triple bonds. Transition Met. Chem. 1984, 9, $360-362$.

(33) The formation of a $\mathrm{CpCo}(\mathrm{V})$ species has been proposed singularly in the cyclotrimerization towards pyridines as a cobalt $(\mathrm{V})$ carbene: Miclo, Y.; Garcia, P.; Evanno, Y.; George, P.; Sevrin, M.; Malacria, M.; Gandon, V.; Aubert, C. Synthesis of Orthogonally Protected Angular Nitrogen Polyheterocycles via CpCo-Catalyzed Pyridine Formation. Synlett 2010, 2314-2318.

(34) Perdew, J. P. Density-functional approximation for the correlation energy of the inhomogeneous electron gas. Phys. Rev. B 1986, 33, 8822-8824.

(35) Schäfer, A.; Huber, C.; Ahlrichs, R. Fully optimized contracted Gaussian basis sets of triple zeta valence quality for atoms Li to Kr. J. Chem. Phys. 1994, 100, 5829-5835.

(36) Hay, P. J.; Wadt, W. R. Ab initio effective core potentials for molecular calculations. Potentials for $\mathrm{K}$ to Au including the outermost core orbitals. J. Chem. Phys. 1985, 82, 299-310. 
(37) Zhao, Y.; Truhlar, D. G. A new local density functional for main-group thermochemistry, transition metal bonding, thermochemical kinetics, and noncovalent interactions. J. Chem. Phys. 2006, 125, No. 194101.

(38) Marenich, A. V.; Cramer, C. J.; Truhlar, D. G. Universal solvation model based on solute electron density and on a continuum model of the solvent defined by the bulk dielectric constant and atomic surface tensions. J. Phys. Chem. B. 2009, 113, 6378-6396.

(39) Liu, J.; Wei, Z.; Jiao, H. Catalytic Activity of Aliphatic PNP Ligated $\mathrm{Co}^{\mathrm{III} / \mathrm{I}}$ Amine and Amido Complexes in Hydrogenation Reaction-Structure, Stability and Substrate dependence. ACS Catal. 2021, 11, 4593-4605.

(40) Wei, Z.; Tian, X.; Bender, M.; Beller, M.; Jiao, H. Mechanisms of $\mathrm{Co}^{\mathrm{II}}$ and Acid Jointly Catalyzed Domino Conversion of $\mathrm{CO}_{2}, \mathrm{H}_{2}$ and $\mathrm{CH}_{3} \mathrm{OH}$ to Dialkoxymethane-A DFT Study. ACS Catal. 2021, 11, 6908-6919.

(41) Frisch, M. J.; Trucks, G. W.; Schlegel, H. B.; Scuseria, G. E.; Robb, M. A.; Cheeseman, J. R.; Scalmani, G.; Barone, V.; Petersson, G. A.; Nakatsuji, H.; Li, X.; Caricato, M.; Marenich, A. V.; Bloino, J.; Janesko, B. G.; Gomperts, R.; Mennucci, B.; Hratchian, H. P.; Ortiz, J. V.; Izmaylov, A. F.; Sonnenberg, J. L.; Williams; Ding, F.; Lipparini, F.; Egidi, F.; Goings, J.; Peng, B.; Petrone, A.; Henderson, T.; Ranasinghe, D.; Zakrzewski, V. G.; Gao, J.; Rega, N.; Zheng, G.; Liang, W.; Hada, M.; Ehara, M.; Toyota, K.; Fukuda, R.; Hasegawa, J.; Ishida, M.; Nakajima, T.; Honda, Y.; Kitao, O.; Nakai, H.; Vreven, T.; Throssell, K.; Montgomery, J. A., Jr.; Peralta, J. E.; Ogliaro, F.; Bearpark, M. J.; Heyd, J. J.; Brothers, E. N.; Kudin, K. N.; Staroverov, V. N.; Keith, T. A.; Kobayashi, R.; Normand, J.; Raghavachari, K.; Rendell, A. P.; Burant, J. C.; Iyengar, S. S.; Tomasi, J.; Cossi, M.; Millam, J. M.; Klene, M.; Adamo, C.; Cammi, R.; Ochterski, J. W.; Martin, R. L.; Morokuma, K.; Farkas, O.; Foresman, J. B.; Fox, D. J.et al. Gaussian 16, revision A.03; Gaussian Inc.: Wallingford, CT, 2016.

(42) The overall formation of carbocycle 1a_dimer is exergonic by $125.6 \mathrm{kcal} / \mathrm{mol}$, even significantly more exothermic than that of the formation of phosphinine 3a' ((99.5 kcal/mol), compare Chart 5 . 